\title{
Synthesis of a dihalogenated pyridinyl silicon rhodamine for mitochondrial imaging by a halogen dance rearrangement
}

\author{
Jessica Matthias ${ }^{1,2}$, Thines Kanagasundaram ${ }^{3,4}$, Klaus Kopka ${ }^{3,5}$ \\ and Carsten S. Kramer ${ }^{\star 3}$
}

\author{
Full Research Paper \\ Address: \\ ${ }^{1}$ Max Planck Institute for Medical Research, Department of Optical \\ Nanoscopy, Jahnstraße 29, 69120 Heidelberg, Germany, ${ }^{2}$ Helmholtz \\ International Graduate School, German Cancer Research Center \\ (DKFZ), Im Neuenheimer Feld 223, 69120 Heidelberg, Germany, \\ ${ }^{3}$ Division of Radiopharmaceutical Chemistry, German Cancer \\ Research Center (DKFZ), Im Neuenheimer Feld 223, 69120 \\ Heidelberg, Germany, ${ }^{4}$ Institute of Inorganic Chemistry, Im \\ Neuenheimer Feld 270, 69120 Heidelberg, Germany and ${ }^{5}$ German \\ Cancer Consortium (DKTK), Heidelberg, Germany \\ Email: \\ Carsten S. Kramer ${ }^{*}$ - c.kramer@dkfz-heidelberg.de \\ * Corresponding author \\ Keywords: \\ halogen-dance reaction; mitochondrial probe; near-infrared (NIR) \\ dyes; one-pot reaction; silicon rhodamines \\ Beilstein J. Org. Chem. 2019, 15, 2333-2343. \\ doi:10.3762/bjoc. 15.226 \\ Received: 31 May 2019 \\ Accepted: 05 September 2019 \\ Published: 01 October 2019 \\ This article is part of the thematic issue "Dyes in modern organic \\ chemistry". \\ Guest Editor: H. Ihmels \\ (C) 2019 Matthias et al.; licensee Beilstein-Institut. \\ License and terms: see end of document.
}

Open Access

\begin{abstract}
Background: Since their first synthesis, silicon xanthenes and the subsequently developed silicon rhodamines (SiR) gained a lot of attention as attractive fluorescence dyes offering a broad field of application. We aimed for the synthesis of a fluorinable pyridinyl silicon rhodamine for the use in multimodal (PET/OI) medical imaging of mitochondria in cancerous cells.

Results: A dihalogenated fluorinatable pyridinyl rhodamine could be successfully synthesized with the high yield of $85 \%$ by application of a halogen dance (HD) rearrangement. The near-infrared dye shows a quantum yield of 0.34 , comparable to other organelle targeting SiR derivatives and absorbs at $665 \mathrm{~nm}\left(\varepsilon_{\max }=34000 \mathrm{M}^{-1} \mathrm{~cm}^{-1}\right)$ and emits at $681 \mathrm{~nm}(\tau=1.9 \mathrm{~ns})$. Using colocalization experiments with MitoTracker ${ }^{\circledR}$ Green FM, we could prove the intrinsic targeting ability to mitochondria in two human cell lines (Pearson coefficient $>0.8$ ). The dye is suitable for live cell STED nanoscopy imaging and shows a nontoxic profile which makes it an appropriate candidate for medical imaging.
\end{abstract}

Conclusions: We present a biocompatible, nontoxic, small molecule near-infrared dye with the option of subsequent radiolabelling and excellent optical properties for medical and bioimaging. As a compound with intrinsic mitochondria targeting ability, the radiolabelled analogue can be applied in multimodal (PET/OI) imaging of mitochondria for diagnostic and therapeutic use in, e.g., cancer patients. 


\section{Introduction}

Since their first synthesis by Fu and co-workers in 2008 [1], silicon xanthenes and the subsequently developed silicon rhodamines $(\mathrm{SiR})$ have drawn a lot of attention as attractive fluorescence dyes offering a broad field of application. Their excellent spectral (absorption and emission bands in the nearinfrared region), photophysical (bright and photostable) and biochemical (biocompatible, biological stable and cell membrane permeable) properties make them useful tools in live cell super-resolution microscopy [2-9], as direct probes for various biomolecules [10-13] or as sensors for metal ions [14-18], $\mathrm{pH}$ [16], voltage [19] or metabolites [20-23]. Several attempts were made, partially supported by DFT calculations, to correlate the dyes' structural features with their optical properties and control the latter by rational dye design [15,24-26]. These investigations led to new silicon rhodamine dyes with enhanced and fine-tuned properties (quantum yield, lifetime, brightness, absorption and emission maxima). A recent review compared the photophysical properties of numerous silicon rhodamines leading to further insights into the correlation of the dyes' chemical structure with their fluorogenic behavior [27] Regarding the quantum yield, Hanaoka et al. have shown that introduction of methyl, methoxy or dimethylamine groups into the benzene moiety of silicon rhodamines could tune the HOMO energy level [15]. Depending on the oxidation potential and the HOMO energy level of the benzene moiety, the quantum yield was greatly altered but absorption and emission bands remained unchanged. Thus, the quantum yield shows a direct connection to the negative value of the HOMO energy level and/or the oxidation potential [15], but it is also influenced by other factors. Nonradiative quenching (e.g., bond rotation) can effectively contribute to depopulation of the fluorophore's excited state [28], yielding a lower quantum yield. However, the rational trends for both radiative and nonradia- tive decays still remain difficult to predict despite theoretical and experimental efforts of the past years [29]. Here we initially assume that, in analogy to BODIPY fluorophores [30], restricted rotation around the xanthene aryl bond should lead to an improved quantum yield.

In Scheme 1 we compile silicon rhodamines with high quantum yields as well as their structural analogues with lower quantum yields. Silicon fluoresceins were excluded from this compilation, although "2-COOH DCTM" [31], "2-COOH DFTM" [31], and "Maryland red" [32] are representatives with quantum yields up to 0.67 . As described previously, azetidine substituents at the xanthene moiety of $\mathbf{5 , 7}$, and 9 lead to an improved quantum yield and to a red shift in comparison to the $N, N$-dimethylaniline analogues $\mathbf{1}, \mathbf{3}$, and $\mathbf{4}$ (Table 1 , entry 1 vs 5,3 vs 7 , and 4 vs 9). In contrast, the 4 -fluoroazetidine moiety in 10 ("JF 635 ") causes a hypsochromic shift without affecting the high quantum yield compared to the azetidine analogue 9 ("JF 646 ") (Table 1, entry 9 vs 10). Comparing the phenyl substituted rhodamine 2 with its 2 '-methyl substituted analogue $\mathbf{3}$, restricted rotation around the xanthene-benzene bond leads to a drastic improvement of the quantum yield from 0.10 to 0.31 (Table 1, entry 2 vs 3 ). Accordingly, rhodamines like 3, 4, 11, or 12 bearing 2'-substituents with A-values between a proton and a methyl group (such as $\mathrm{F}$ and $\mathrm{Cl}$ ) show quantum yields from 0.19 (for $\mathrm{F}$ ) [23] to 0.30 (for $\mathrm{Cl}$ ) [23]. This observation leads us to the hypothesis that the quantum yield correlates positively with the bulkiness of the phenylic 2'-substituent, which restricts the rotation around the xanthene-benzene bond more strongly the larger it is.

Remarkably, dyes 1, 5 and $\mathbf{6}$ already possess moderate to high quantum yields without any benzene moiety (Table 1, entries 1 ,<smiles></smiles>

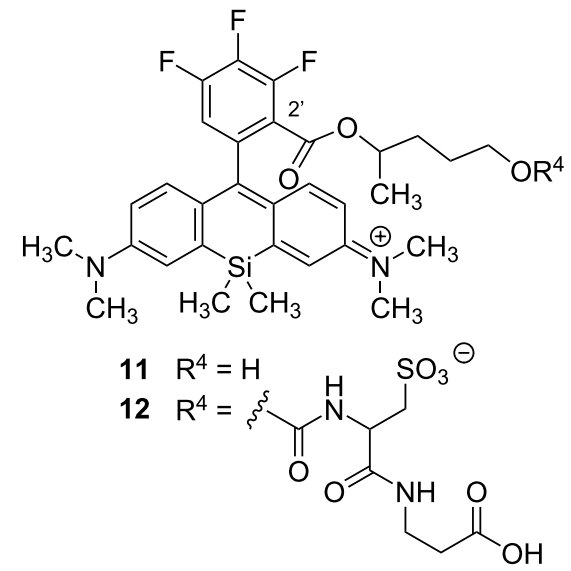


Table 1: Comparison of optical properties of different silicon rhodamines.

\begin{tabular}{|c|c|c|c|c|c|c|c|}
\hline Entry & $N R^{1} R^{2}$ & $\mathrm{R}^{3}$ & & $\lambda_{\mathrm{abs}}$ & $\lambda_{\mathrm{em}}$ & $\Phi$ & Ref \\
\hline 1 & $\mathrm{~N}\left(\mathrm{CH}_{3}\right)_{2}$ & $\mathrm{H}$ & $\begin{array}{c}1 \\
(\mathrm{SiP})\end{array}$ & 634 & 648 & $0.42^{a, b}$ & [15] \\
\hline 2 & $\mathrm{~N}\left(\mathrm{CH}_{3}\right)_{2}$ & $\mathrm{Ph}$ & 2 & 646 & 667 & $0.10^{\mathrm{b}, \mathrm{c}}$ & [33] \\
\hline 3 & $\mathrm{~N}\left(\mathrm{CH}_{3}\right)_{2}$ & $2-\mathrm{CH}_{3}-\mathrm{Ph}$ & 3 & 646 & 660 & $0.31^{a, b}$ & [15] \\
\hline 4 & $\mathrm{~N}\left(\mathrm{CH}_{3}\right)_{2}$ & 2-COOH-Ph & 4 & 643 & 662 & $0.41^{\mathrm{d}, \mathrm{e}}$ & [24] \\
\hline 5 & azetidine & $\mathrm{H}$ & 5 & 636 & 649 & $0.62^{\mathrm{d}, \mathrm{e}}$ & [32] \\
\hline 6 & azetidine & $\mathrm{COOH}$ & 6 & 641 & 657 & $0.26^{\mathrm{d}, \mathrm{e}}$ & [32] \\
\hline 7 & azetidine & $2-\mathrm{CH}_{3}-\mathrm{Ph}$ & 7 & 649 & 663 & $0.47^{\mathrm{d}, \mathrm{e}}$ & [32] \\
\hline 8 & azetidine & $2-\mathrm{CH}_{3}-6-\mathrm{CH}_{3}-\mathrm{Ph}$ & 8 & 651 & 664 & $0.51^{\mathrm{d}, \mathrm{e}}$ & [32] \\
\hline 9 & azetidine & 2-COOH-Ph & $\begin{array}{c}9 \\
\left(\mathrm{JF}_{646}\right)\end{array}$ & 646 & 664 & $0.54^{\mathrm{d}, \mathrm{e}}$ & [24] \\
\hline 10 & 3-fluoroazetidine & 2-COOH-Ph & $\begin{array}{c}10 \\
\left(J_{635}\right)\end{array}$ & 635 & 652 & $0.56^{\mathrm{d}, \mathrm{e}}$ & [25] \\
\hline 11 & & & 11 & 662 & 680 & $0.66^{f, g, h}$ & [34] \\
\hline 12 & & & 12 & 663 & 680 & $0.70^{f, h}$ & [34] \\
\hline 13 & $\mathrm{~N}\left(\mathrm{CH}_{3}\right)_{2}$ & pyridin-4-yl & 13 & 655 & 680 & $0.12^{\mathrm{c}, \mathrm{e}}$ & [35] \\
\hline 14 & azetidine & 3-methylpyridin-4-yl & 14 & 656 & 670 & $0.48^{\mathrm{d}, \mathrm{e}}$ & \\
\hline
\end{tabular}

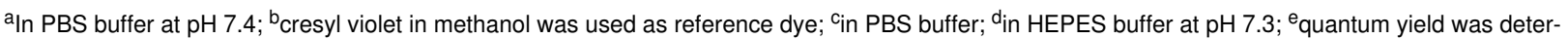
mined by absolute measurement; ${ }^{\text {in }}$ water; ${ }^{9}$ the corresponding isopropyl ester showed a quantum yield of $0.60 ;{ }^{h}$ quantum yield determined in water with the reference dye Atto AZ 237.

5 and 6). The fluorophores 11 and $\mathbf{1 2}$ exhibit values of 0.66 and 0.70 and have, to the best of our knowledge, the highest quantum yields known amongst silicon rhodamines (Scheme 1, Table 1, entries 11 and 12). One reason might be the bulkiness of the ester group in 2'-position, an isopropyl ester derivative; another one might be the effects of the fluorine atoms and the ester group on the HOMO energy level of the benzene moiety.

Since our group is interested in PET-active near-infrared (NIR) dyes for bimodal medical imaging (PET/optical imaging (OI)), we wanted to develop the pyridinyl-substituted silicon rhodamine $\mathbf{1 5}$, in which the 2-halopyridine moiety can easily be radiofluorinated to the PET-active dye 16 (Scheme 2, for examples on radiolabelling of 2-halopyridines see [36-38] and references therein). While the PET modality is highly interesting for precise medical imaging of diseases, the fluorescence modality can be utilized for medical interventions, such as fluorescenceguided surgery or sentinel lymph node detection or for histopathological analyses of biopsy material.

To date, only two pyridinyl-substituted silicon rhodamines have been published. Dye 13 (Scheme 1, Table 1, entry 13) shows good water solubility, has a quantum yield of 0.12 and offers<smiles>[R]c1nccc(Br)c1C1=C2C=CC(=[N+](C)[O-])C=C2[Si](C)(C)c2cc(N(C)C)ccc21</smiles>

$15 \mathrm{R}=\mathrm{Cl}$ $16 \mathrm{R}=\left[{ }^{19} \mathrm{~F}\right] \mathrm{F}$ or $\left[{ }^{18} \mathrm{~F}\right] \mathrm{F}$<smiles>C=C=CCc1ccc2c(c1)[Si](C)(C)c1cc(N(C)C)ccc1C2=O</smiles>

17 2 steps from 3-bromo- $N, N$-dimethylaniline 
intrinsic targeting ability to lysosomes [35]. Pyridine silicon rhodamine 14 (Table 1, entry 14) has an improved quantum yield of 0.48 [32], presumably due to the restricted rotation of the xanthene pyridine bond.

The 2-chloropyridinyl moiety in $\mathbf{1 5}$ is not only attractive because of its option for convenient fluorination, but also since its intrinsic targeting ability to acidic cellular compartments (such as the lysosomal-selective fluorophore 13). We assumed that our proposed bimodal fluorophore would show a better selectivity for mitochondria because of its more lipophilic nature (clogP for $\mathbf{1 5} 3.712$, for $\mathbf{1 6} 3.142$ ) compared to $\mathbf{1 3}$ (clogP 2.136). Medical imaging of mitochondrial activity is highly interesting for various indications, ranging from neurodegenerative and metabolic diseases to ischemic injuries, necrosis, therapy response and cancer [39-43]. Because many cancer cells have a higher mitochondrial membrane potential than nontransformed cells $[41,44,45]$, we believe that our imaging agent will achieve a reasonable tumor-to-background ratio.

Lipophilic cations such as the phosphonium cation or rhodamines are known to accumulate selectively within the mitochondria, driven by the mitochondrial plasma membrane potential $[39,40]$. Thereby, the high lipophilicity facilitates the diffusion through the lipid bilayers of the cell and mitochondrial membranes. Recently, a silicon rhodamine for selective mitochondrial staining was developed by conjugation of the SiR core with ten different amines varying in lipophilicity [46]. The authors showed that the optimal range of clogP values for mitochondrial targeting ranges from 5.50 to 6.33 .

As mentioned above, the pyridinyl-substituted silicon rhodamines $\mathbf{1 3}$ and $\mathbf{1 4}$ are dyes with spectral properties in the near-infrared region. Dye 14 possess the higher quantum yield not only due to the azetidine substituents at the xanthene moiety, but also because of the restricted bond rotation owing to the 3'-methyl (pyridine numbering) group. Since the smaller 2'-fluorine substituent in $\mathbf{1 6}$ should lead to a decrease in quantum yield compared to $\mathbf{1 5}$, we aimed for a molecule with an additional bulky 4'-substituent such as bromine. The bromine should not only alter the HOMO energy level of $\mathbf{1 6}$ in a favourable way, it can also be used for further functionalization. Until now, no silicon rhodamines are known that bear two phenylic halogen substituents $(\mathrm{Cl} / \mathrm{Cl}, \mathrm{Cl} / \mathrm{Br}, \mathrm{Br} / \mathrm{Br}$ nor combinations with $\mathrm{F}$ ) at the positions adjacent to the xanthene benzene bond. The same holds true for the oxygen counterparts with a dihalogenated pyridinyl motif. In fact, only two pyridinyl silicon rhodamines (13 and 14) are known so far, although halogenated pyridines are highly interesting for further functionalization or vector conjugation by nucleophilic aromatic substitu- tion. For the implementation of the dihalogenated pyridine motif into the silicon rhodamine scaffold, we considered using a halogen dance (HD) reaction of 3-bromo-2-chloropyridine (19) to $\mathbf{1 8}$ followed by a condensation with silicon xanthone 17, which is accessible in two steps from 3-bromo- $N, N$-dimethylaniline. The rearrangement of halo pyridine 19, initiated by a halogen metal exchange with $n$-BuLi, was initially published and investigated by Mallet et al. who also investigated and termed the mechanism "homotransmetallation" [47]. The HD rearrangement reaction in general is an excellent method for the construction of highly substituted carbo- and heterocyclic systems (e.g., tetrasubstituted pyridines [48]) with substitution patterns difficult to obtain otherwise [49-51].

\section{Results and Discussion Approaches to synthesize the pyridinyl silicon rhodamine 15}

Table 2 and Scheme 3 summarize the experimental results towards the synthesis of the radiofluorinatable near-infrared dye 15. To initiate the HD reaction, 3-bromo-2-chloropyridine (19) had first to be lithiated. After $30 \mathrm{~min}$ at $-78{ }^{\circ} \mathrm{C}$, the silicon xanthone $\mathbf{1 7}$ was added at the same temperature and the reaction mixture was subsequently warmed up to room temperature and stirred for varying time periods. By using $t$-BuLi as a lithiation reagent, the desired dye 15 was obtained at just $14 \%$ yield as a deep blue solid (Scheme 3, Table 2, entry 1). Owing to the mechanism of the homotransmetallation, the HD rearrangement of $\mathbf{1 9}$ is conducted with substoichiometric amounts of the lithiating agent (usually 0.5 equiv $n$-BuLi for 1 equiv 19) $[47,49]$. Thus, we tried the reaction with 0.9 equiv of $t$-BuLi (Table 2, entry 2) and 0.5 equiv of $n$-BuLi (Table 2, entry 3 ), but the desired product was again obtained in poor yields with lots of unreacted starting material 17. According to the mechanism of the halogen-metal exchange with $t$-BuLi, one equivalent of the base is used for the lithiation, while a second equivalent base eliminates hydrogen bromide from the resulting

\begin{tabular}{|c|c|c|c|}
\hline Entry & $\begin{array}{l}\text { Equiv of lithiation } \\
\text { reagent }\end{array}$ & Equiv of 19 & Yield 15 \\
\hline 1 & $20 t$-BuLi & 10 & $14 \%^{a}$ \\
\hline 2 & $9 t$-BuLi & 10 & $\begin{array}{l}14 \% \%^{b} \\
28 \% b, c\end{array}$ \\
\hline 3 & $5 n$-BuLi & 10 & $11 \% \%^{d}$ \\
\hline 4 & $40 t$-BuLi & 20 & $85 \% \%^{e}$ \\
\hline
\end{tabular}

a $1.5 \mathrm{~h}$ reaction time after addition of 1 equiv of xanthone 17; b24 $\mathrm{h}$ reaction time; 'cyield based on recovered starting material of xanthone $17{ }^{d} 5 \mathrm{~h}$ reaction time, ${ }^{\mathrm{e}} 4 \mathrm{~h}$ reaction time. 


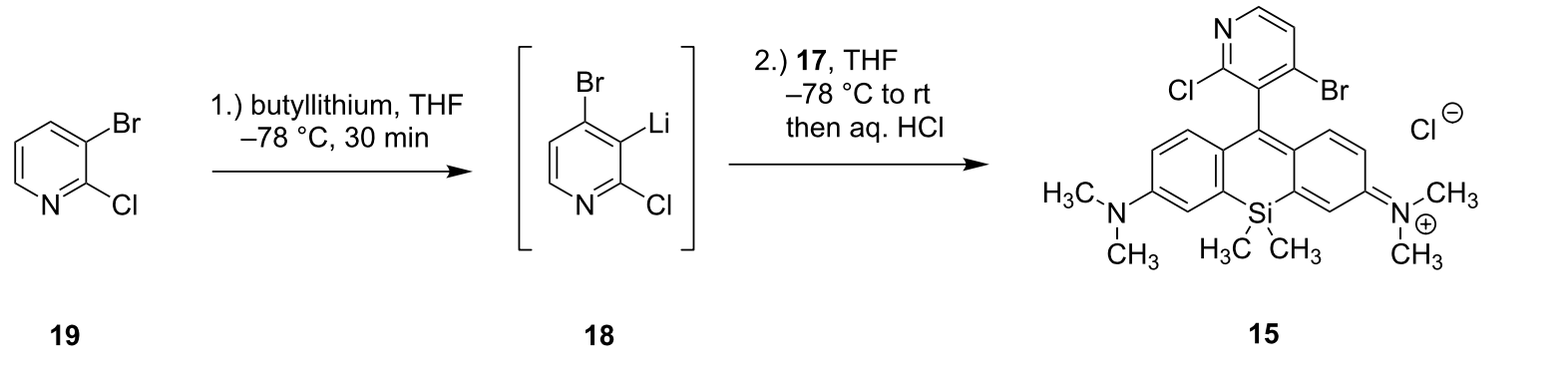

Scheme 3: Optimization of the HD rearrangement of 19 and subsequent reaction with xanthone 17 to the silicon rhodamine dye 15.

$t$-BuBr. Therefore, entries 2 and 3 (Table 2) represent the use of approx. 0.5 equiv base for 1 equiv of $\mathbf{1 9}$. After lithiation of $\mathbf{1 9}$, the metallated intermediate (2-chloropyridin-3-yl)lithium reacts again with starting material 19 resulting, after several steps (the so called halogen dance), in the lithiated pyridine intermediate 18 that can add to the silicon xanthone 17. Low temperatures for the HD reaction are required when more equivalents of the base are used to maintain a coexistence of $\mathbf{1 9}$ and its lithiated analogue. Using high excess of $\mathbf{1 9}$ could force the reaction to completeness leading to the dihalogenated pyridinyl silicon rhodamine in $85 \%$ yield without any monohalogenated byproduct and no necessity of HPLC purification.

Although 15 can be coupled or further functionalized at the bromine via a nucleophilic substitution, we explored also if the ester analogue tert-butyl 5-bromo-6-chloronicotinate could undergo a HD reaction with subsequent xanthone addition. The reaction did not lead to any product, neither with $n$-BuLi nor with $t$-BuLi. However, it is noteworthy that no HD reactions of nicotinic acids can be found in the literature. In fact, if 2,3dihalogenated pyridines are used for the HD rearrangement as starting materials, only methyl groups are tolerated as carbon substituents.

\section{Optical properties of the pyridinyl silicon rhodamine 15}

The dihalogenated pyridinyl SiR $\mathbf{1 5}$ has an absorption peak at $665 \mathrm{~nm}\left(\varepsilon_{\max }=34000 \mathrm{M}^{-1} \mathrm{~cm}^{-1}\right)$ and an emission peak at $681 \mathrm{~nm}(\tau=1.9 \mathrm{~ns}$, Figure S3a, Table S2a, Supporting Information File 1) (measured in PBS buffer pH 7.4). It shows a redshift of approx. $10 \mathrm{~nm}$ in absorption and emission compared to the azetidine-substituted pyridinyl dye $\mathbf{1 4}$ and a $10 \mathrm{~nm}$ redshifted absorption with unchanged emission compared to pyridinyl dye $\mathbf{1 3}$ (Figure 1a). The quantum yield is with 0.34 (measured in PBS buffer pH 7.4, Figure S2a, Table S1a, Supporting Information File 1), remarkably higher than the value of pyridinyl dye 13. This fact could be explained with rotation restriction around the pyridinyl-xanthene bond and/or with beneficial effects of the halogens on the HOMO energy level. Nevertheless, the pyridinyl SiR $\mathbf{1 4}$ performs better due to the addition contributions of the azetidine rings.

Next, we examined the targeting ability to mitochondria of the dihalogenated dye $\mathbf{1 5}$ by colocalization experiments with the commercially available mitochondria staining reagent MitoTracker ${ }^{\circledR}$ Green FM (Figure 1a,b and Figure S4a,b, Supporting Information File 2). To determine the Pearson coefficient for colocalization of SiR 15 with MitoTracker ${ }^{\circledR}$ Green FM, HeLa cells (human cervical cancer cells) and U2OS cells (human bone osteosarcoma epithelial cells) were co-stained with these dyes. The Pearson coefficients are reasonably high and similar for both cell lines (HeLa cells: $0.85 \pm 0.05(N=20)$, U2OS cells: $0.81 \pm 0.05(N=27))$ supporting the application of SiR 15 as a specific NIR mito tracker probe. Pearson coefficients for selective mitochondria staining $>0.8$ correlate with much higher lipophilicity (clogP over 4.95). Especially SiR-Mito 8 offers a comparable quantum yield to dye $\mathbf{1 5}$ ( $\varepsilon$ and therefore brightness not available) combined with a Pearson coefficient $\geq 0.9$ [46]. However, dye $\mathbf{1 5}$ has the benefit of further red-shifted absorption and emission properties as well as a photostability that allows for STED (stimulated emission depletion) nanoscopy $[52,53]$.

As the 2-chloropyridinyl moiety in SiR dye $\mathbf{1 5}$ targets acidic cellular compartments in general, we additionally investigated potential lysosomal colocalization. Co-staining HeLa and U2OS cells with SiR dye $\mathbf{1 5}$ and the commercially available lysosomal staining reagent LysoTracker ${ }^{\mathrm{TM}}$ Green DND-26 showed absence of any lysosomal targeting ability and confirmed specific mitochondrial staining (Figure S4c,d, Supporting Information File 1).

Medical imaging agents are highly interesting especially if they can address multiple questions or can be applied for different purposes simultaneously, because they must undergo an expensive regulatory process before they attain approval for the 

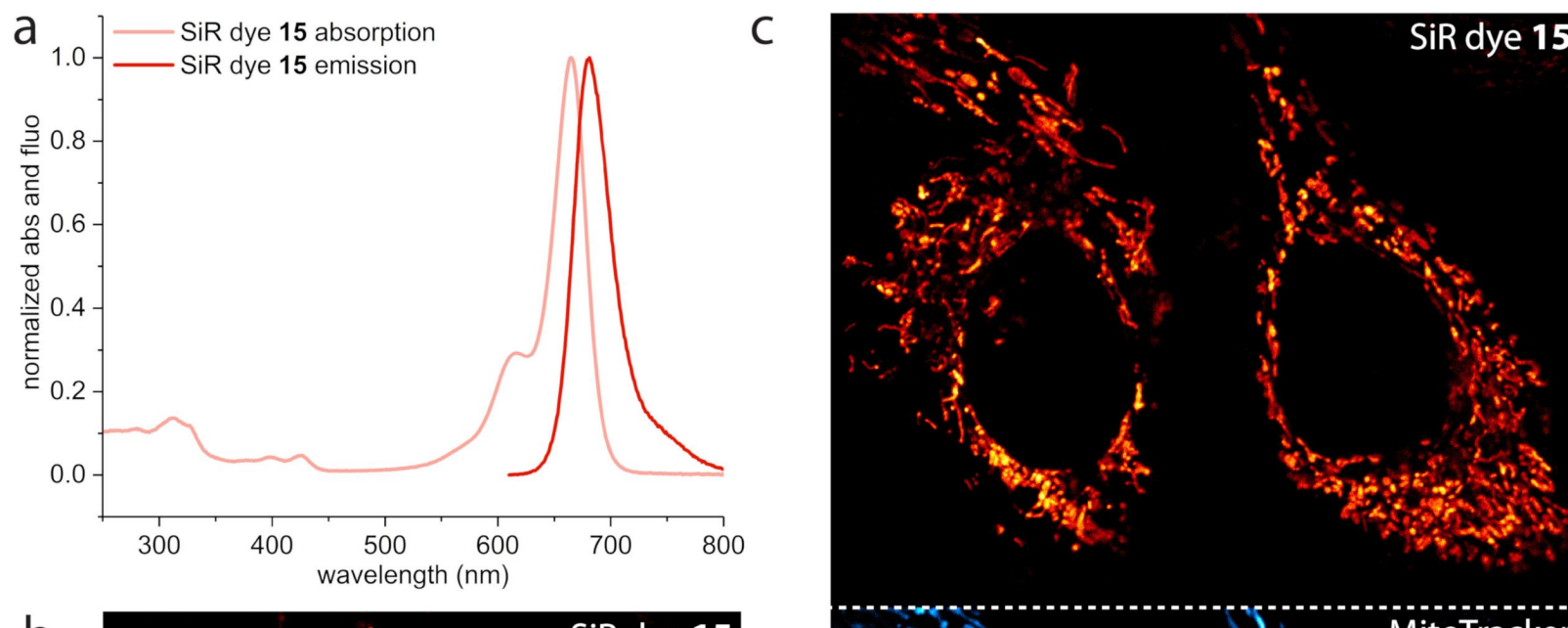

b
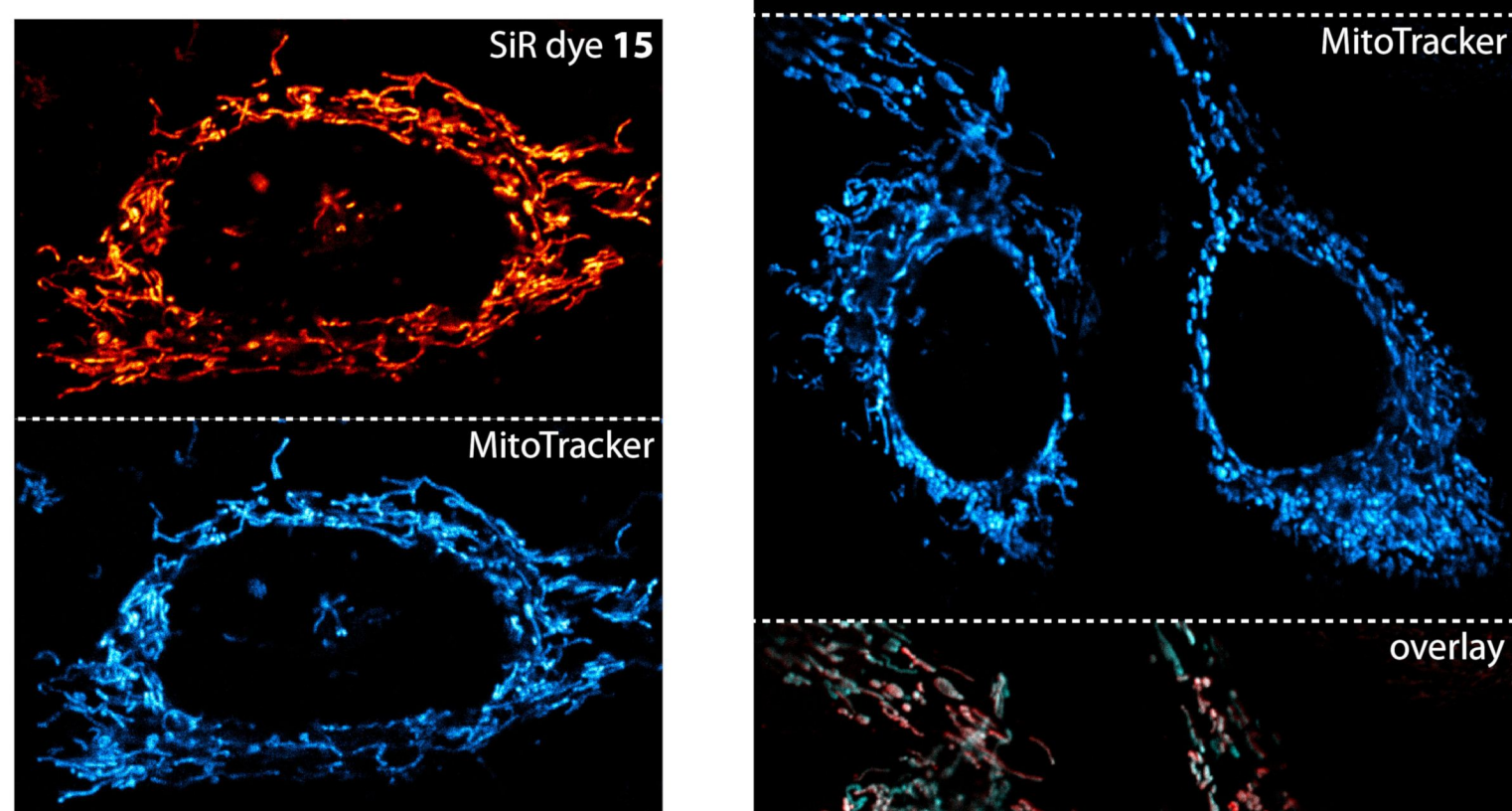

overlay
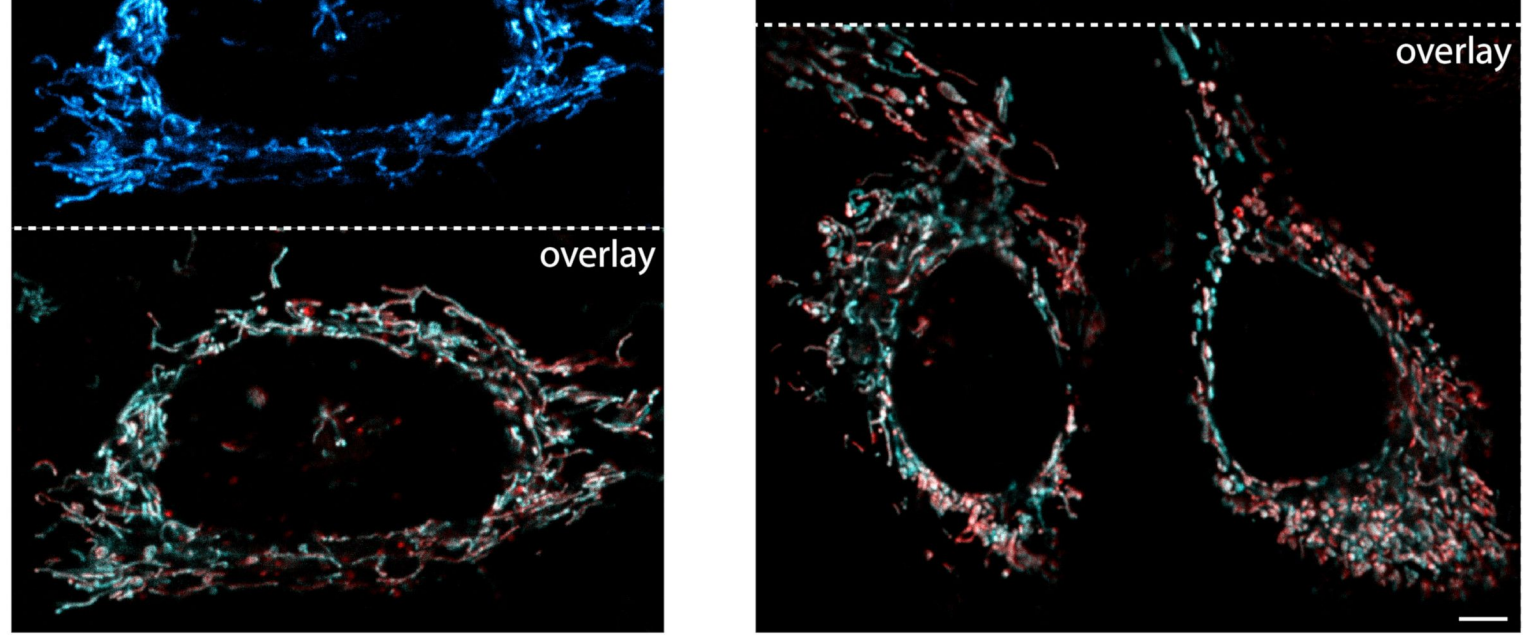

Figure 1: (a) Absorption and fluorescence emission spectra of dye 15 measured in PBS buffer pH 7.4. (b, c) Colocalization experiment of dye 15 (red) and MitoTracker ${ }^{\circledR}$ Green FM (cyan) in living HeLa (b) and U2OS (c) cells supporting the application of dye 15 as a specific NIR mito tracker probe. Both cell lines were incubated for $0.5 \mathrm{~h}$ with $1 \mu \mathrm{M}$ of dye 15 and $100 \mathrm{nM}$ of MitoTracker ${ }^{\circledR}$ Green FM, washed and imaged with excitation at $470 \mathrm{~nm}$ $(380 \mu \mathrm{W})$ and $652 \mathrm{~nm}(7.5 \mu \mathrm{W})$. Confocal images are color shift and background corrected, scale bar $5 \mu \mathrm{m}$.

market. Therefore, we are interested also in purposes other than PET imaging or macroscopic fluorescence imaging. Histopathological examinations of biopsy material on subcellular level need high image quality. Thus, the option to use our proposed bimodal dye in STED nanoscopy would be advantageous. For example, Giedt et al. could show that analysis of mitochondrial 
a
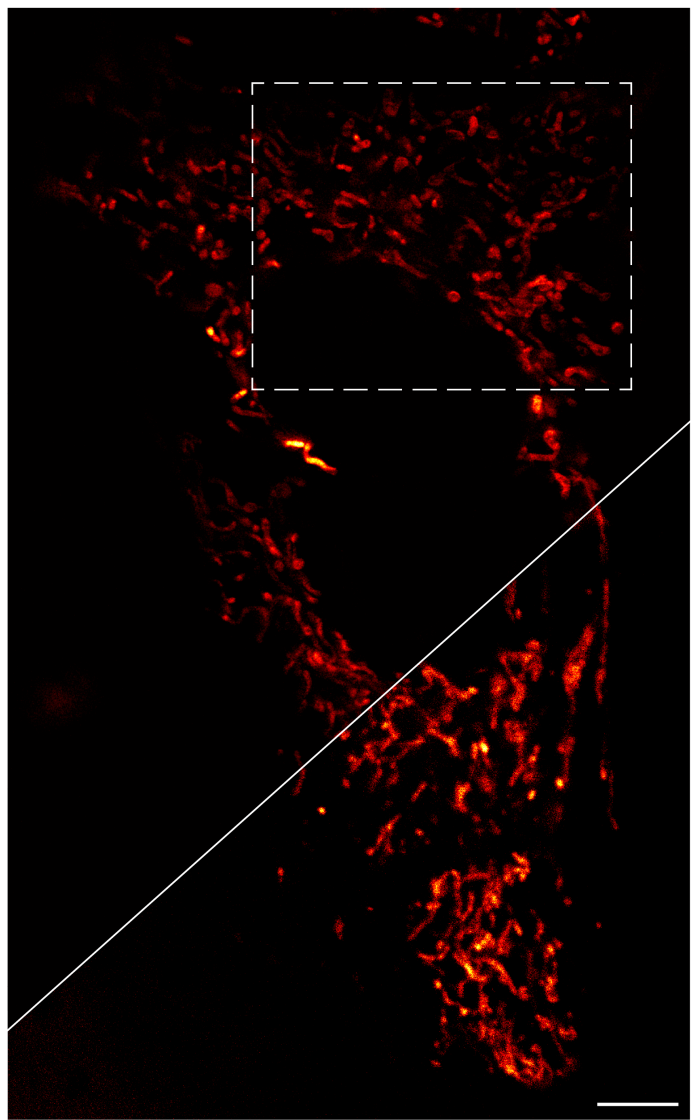

C

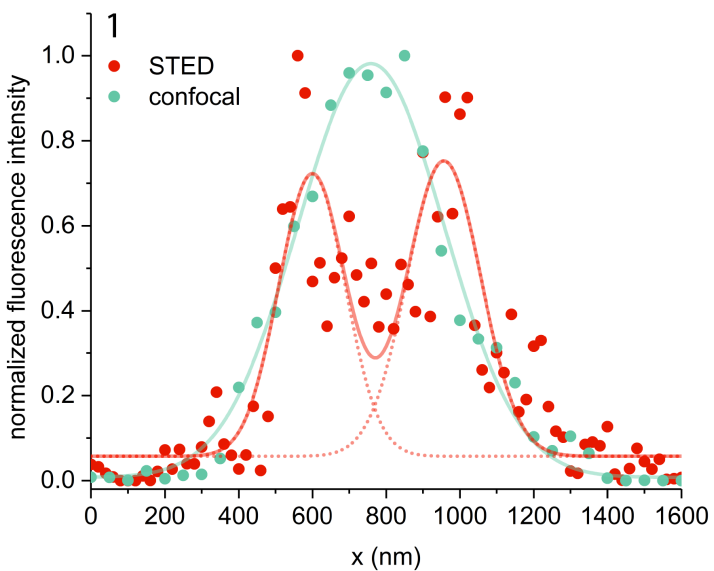

b
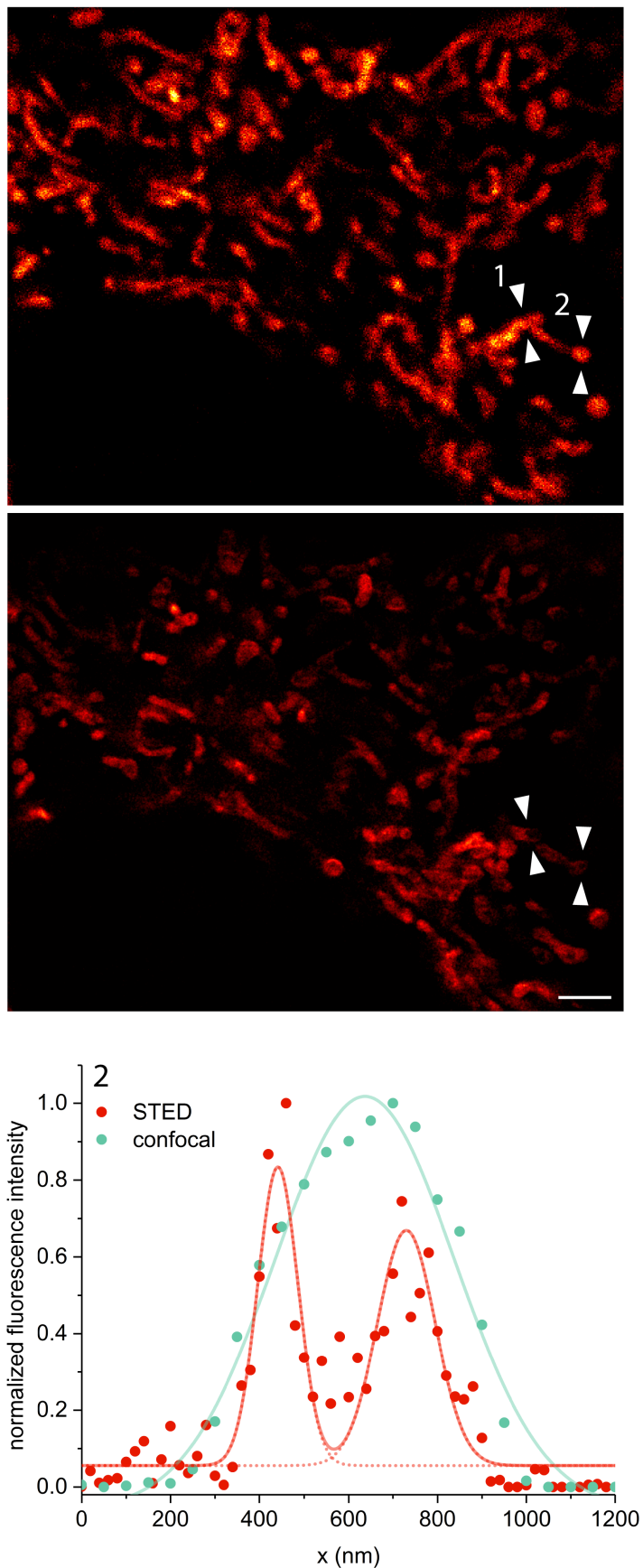

Figure 2: STED and confocal images of the mitochondrial network in living HeLa cells stained with $1 \mu \mathrm{M}$ SiR dye 15 for $1 \mathrm{~h}$. (a) STED image (excitation at $652 \mathrm{~nm}$ with $15 \mu \mathrm{W}$, depletion at $775 \mathrm{~nm}$ with $40 \mathrm{~mW}$ ) with the corresponding confocal data (excitation at $652 \mathrm{~nm}$ with $7.5 \mu \mathrm{W}$ ) in the bottom right corner. STED image is background subtracted and linearly deconvolved (Lorentzian PSF), confocal image is only background subtracted, scale bar $5 \mu \mathrm{m}$. (b) Magnified view of the region marked in (a) in confocal (top) and STED mode (bottom), scale bar $2 \mu \mathrm{m}$. (c) Line profiles marked in (b) proving the gain in spatial resolution of STED (red) compared to confocal (cyan). Line profiles were taken from only background corrected (not deconvolved) data (Figure S8, Supporting Information File 1), counts were averaged over five pixels, normalized and fitted to a single (confocal) or double (STED) Gaussian function. To avoid photobleaching, the STED power was set as low as possible but as high as necessary to resolve the tubular structure of mitochondria resulting in full width half maxima (FWHM) of $219 \pm 15 \mathrm{~nm}$ (1, left), $306 \pm 21 \mathrm{~nm}(1$, right), $114 \pm 7 \mathrm{~nm}(2$, left) and $200 \pm 9$ (2, right). The peak to peak distances are $363 \mathrm{~nm}$ (1) and $294 \mathrm{~nm}$ (2). The FWHM of the confocal fits are $470 \pm 15 \mathrm{~nm}(1)$ and $474 \pm 25 \mathrm{~nm}(2)$.

morphology can be used as a biomarker for cancer phenotype assignment and for drug response analysis [54]. For STED imaging, HeLa cells were stained for $1 \mathrm{~h}$ with $1 \mu \mathrm{M}$ of dye $\mathbf{1 5}$, washed and imaged live. Figure 2 and Figure S5, Supporting Information File 1, compare STED images with their corresponding confocal images. By resolving the tubular structure of 
mitochondria, we prove successful application of our mitochondria-selective pyridinyl SiR 15 in STED nanoscopy.

\section{Toxicity of the pyridinyl silicon rhodamine $\mathbf{1 5}$}

Although for PET examinations only nano- or picomolar amounts of the radiopharmaceutical compound are needed, medical applications of fluorescence dyes (e.g., fluorescenceguided interventions) require larger amounts of material. Therefore, cytotoxicity testing is necessary for our proposed bimodal imaging agent $\mathbf{1 6}$ and its precursor $\mathbf{1 5}$. For toxicity assessment, the frequency and duration of cell division with and without incubation with dye $\mathbf{1 5}$ was analyzed via time-lapse holographic imaging (Figure 3). U2OS cells were incubated with $1 \mu \mathrm{M}$ dye $\mathbf{1 5}$ in medium for $1 \mathrm{~h}$ and, after washing with dye free medium, continually imaged over a period of $14.5 \mathrm{~h}$ using a holographic incubator microscope. The analysis of the data revealed that the frequency and duration of cell division of the cells incubated with dye $\mathbf{1 5}$ show no difference to the untreated control (frequency of cell division with SiR dye 15: $0.30 \pm 0.05$ divisions per cell, without dye: $0.32 \pm 0.06$ divisions per cell, for division duration see Figure S7, Supporting Information File 1). These results are supported by cell count and confluency analysis (Figure S9, Supporting Information File 1). In summary, we conclude that dye $\mathbf{1 5}$ does not show any significant cytotoxicity in this human cell line. Comparable experiments with HeLa cells strengthen these results (data not shown).

\section{Conclusion}

We have proven the feasibility of synthesizing a pyridinyl silicon rhodamine dye with two halogen atoms adjacent to the xanthene-pyridine bond by application of a halogen dance rearrangement. By our optimized procedure, we have obtained the dye $\mathbf{1 5}$ at high yield and without the necessity of HPLC purification. The chlorine atom in 2'-position can potentially be used to introduce the PET radionuclide fluorine-18 while the bromine atom serves as a constraint against rotation around the xanthene-pyridine bond as well as a leverage point for further linkage. The quantum yield is reasonably high (0.34). However, despite the improved molecule rigidity and thus presumably less nonradiative decay, dye $\mathbf{1 5}$ does not outperform the quantum yield of monosubstituted pyridine SiR 14. Additional experiments (supported by DFT calculations) on the orbital effects of both halogens and the nitrogen position in the pyridine ring are needed to explain these effects with confidence.

In addition, our SiR dye $\mathbf{1 5}$ displays photophysical properties (extinction coefficient, quantum yield, lifetime) in the same range, but rather at the lower end, compared to other near-infrared silicon rhodamine derivatives with similar spectral properties $[3,4,7]$. However, it is in line with the group of SiR derivatives directly targeting certain cellular structures or organelles [7,55-57] and extends this list with a NIR mito tracker ${ }^{\circledR}$ probe.

Just like the recently published squaraine variant dye MitoESq635 [58], our SiR dye 15 offers the option of imaging mitochondria in living cells using STED nanoscopy without the necessity of an additional tagging step. In contrast to MitoESq635, our SiR dye 15 selectively stains mitochondria without background from unspecific membrane staining. However, higher photostability and a lower saturation intensity for STED result in a better performance in time-lapse live cell STED imaging of MitoESq-635. Taken together, our SiR dye $\mathbf{1 5}$ is a valid compromise between MitoESq-635 and SiR-Mito 8 offering nontoxic, specific mitochondrial staining in live cell STED imaging.

In summary, we present a biocompatible, nontoxic, small molecule near-infrared dye with the option of subsequent radiolabelling and excellent optical properties for biomedical imaging. As a compound with intrinsic mitochondria targeting ability, the radiolabelled analogue can find application in multimodal (PET/OI) imaging of mitochondria for diagnostic and therapeutic use in, e.g., cancer patients. (Radio)fluorination of dye $\mathbf{1 5}$ is the subject of ongoing research and will be presented elsewhere.

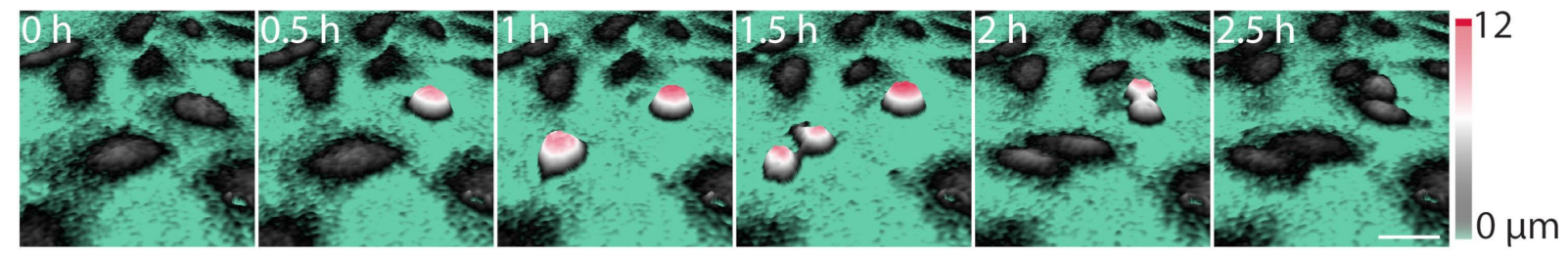

Figure 3: Exemplary holographic image sequence of two cell divisions of U2OS cells treated with $1 \mu \mathrm{M}$ of dye 15. Dividing cells round up and can be distinguished from non-dividing cells by height. After incubation with $1 \mu \mathrm{M}$ dye 15 for $1 \mathrm{~h}$, the cells were washed and then holographically imaged using a HoloMonitor ${ }^{\circledR}$ M4 time-lapse cytometer. Cell proliferation was followed for $14.5 \mathrm{~h}$ (30 min between images) and corresponding time-lapse movies are available in Supporting Information Files 2-5, scale bar $50 \mu \mathrm{m}$. 


\section{Supporting Information}

Synthesis of dye 15, its optical characterization and detailed information on microscopy experiments, including videos showing undisturbed cell proliferation in U2OS cells incubated with $1 \mu \mathrm{M}$ of dye $\mathbf{1 5}$ for $1 \mathrm{~h}$ compared to untreated $\mathrm{U} 2 \mathrm{OS}$ cells are given.

\section{Supporting Information File 1}

Experimental and analytical data, spectra, live cell imaging and assessment of cytotoxicity.

[https://www.beilstein-journals.org/bjoc/content/ supplementary/1860-5397-15-226-S1.pdf]

\section{Supporting Information File 2}

Independent experiment assessing cell division of U2OS cells after treatment with $1 \mu \mathrm{M}$ SiR dye $\mathbf{1 5}$. [https://www.beilstein-journals.org/bjoc/content/ supplementary/1860-5397-15-226-S2.avi]

\section{Supporting Information File 3}

Independent experiment assessing cell division of U2OS cells after treatment with $1 \mu \mathrm{M} \mathrm{SiR}$ dye $\mathbf{1 5}$. [https://www.beilstein-journals.org/bjoc/content/ supplementary/1860-5397-15-226-S3.avi]

\section{Supporting Information File 4}

Independent control experiment assessing undisturbed cell division of U2OS cells.

[https://www.beilstein-journals.org/bjoc/content/ supplementary/1860-5397-15-226-S4.avi]

\section{Supporting Information File 5}

Independent control experiment assessing undisturbed cell division of U2OS cells.

[https://www.beilstein-journals.org/bjoc/content/ supplementary/1860-5397-15-226-S5.avi]

\section{Acknowledgements}

We are very grateful to the Wilhelm Sander Stiftung for a grant on bimodal tumor tracers (2018.024.1). We thank Yvonne Remde for support with synthesis, Dr. Mariano Bossi for support with spectroscopic characterization, Dr. Rifka Vlijm for support with image analysis and Dr. Johann Engelhardt for construction of and support with the microscope setup.

\section{ORCID ${ }^{\circledR}$ iDs}

Jessica Matthias - https://orcid.org/0000-0001-6560-2174 Thines Kanagasundaram - https://orcid.org/0000-0001-8265-8591 Klaus Kopka - https://orcid.org/0000-0003-4846-1271
Carsten S. Kramer - https://orcid.org/0000-0001-9932-423X

\section{References}

1. Fu, M.; Xiao, Y.; Qian, X.; Zhao, D.; Xu, Y. Chem. Commun. 2008, 1780-1782. doi:10.1039/b718544h

2. Thompson, A. D.; Omar, M. H.; Rivera-Molina, F.; Xi, Z.; Koleske, A. J.; Toomre, D. K.; Schepartz, A. Angew. Chem., Int. Ed. 2017, 56, 10408-10412. doi:10.1002/anie.201704783

3. Butkevich, A. N.; Ta, H.; Ratz, M.; Stoldt, S.; Jakobs, S.; Belov, V. N.; Hell, S. W. ACS Chem. Biol. 2018, 13, 475-480. doi:10.1021/acschembio.7b00616

4. Butkevich, A. N.; Mitronova, G. Y.; Sidenstein, S. C.; Klocke, J. L.; Kamin, D.; Meineke, D. N. H.; D'Este, E.; Kraemer, P.-T.; Danzl, J. G.; Belov, V. N.; Hell, S. W. Angew. Chem., Int. Ed. 2016, 55, 3290-3294. doi:10.1002/anie.201511018

5. Kozma, E.; Estrada Girona, G.; Paci, G.; Lemke, E. A.; Kele, P. Chem. Commun. 2017, 53, 6696-6699. doi:10.1039/c7cc02212c

6. Grimm, J. B.; Klein, T.; Kopek, B. G.; Shtengel, G.; Hess, H. F.; Sauer, M.; Lavis, L. D. Angew. Chem., Int. Ed. 2016, 55, 1723-1727. doi:10.1002/anie.201509649

7. Lukinavičius, G.; Reymond, L.; Umezawa, K.; Sallin, O.; D’Este, E.; Göttfert, F.; Ta, H.; Hell, S. W.; Urano, Y.; Johnsson, K. J. Am. Chem. Soc. 2016, 138, 9365-9368. doi:10.1021/jacs.6b04782

8. Takakura, H.; Zhang, Y.; Erdmann, R. S.; Thompson, A. D.; Lin, Y.; McNellis, B.; Rivera-Molina, F.; Uno, S.-n.; Kamiya, M.; Urano, Y.; Rothman, J. E.; Bewersdorf, J.; Schepartz, A.; Toomre, D. Nat. Biotechnol. 2017, 35, 773-780. doi:10.1038/nbt.3876

9. Lukinavičius, G.; Umezawa, K.; Olivier, N.; Honigmann, A.; Yang, G.; Plass, T.; Mueller, V.; Reymond, L.; Corrêa, I. R., Jr.; Luo, Z.-G.; Schultz, C.; Lemke, E. A.; Heppenstall, P.; Eggeling, C.; Manley, S.; Johnsson, K. Nat. Chem. 2013, 5, 132-139. doi:10.1038/nchem.1546

10. Shieh, P.; Siegrist, M. S.; Cullen, A. J.; Bertozzi, C. R. Proc. Natl. Acad. Sci. U. S. A. 2014, 111, 5456-5461. doi:10.1073/pnas.1322727111

11. Iwatate, R. J.; Kamiya, M.; Umezawa, K.; Kashima, H.; Nakadate, M.; Kojima, R.; Urano, Y. Bioconjugate Chem. 2018, 29, 241-244. doi:10.1021/acs.bioconjchem.7b00776

12. Kim, E.; Yang, K. S.; Kohler, R. H.; Dubach, J. M.; Mikula, H.; Weissleder, R. Bioconjugate Chem. 2015, 26, 1513-1518. doi:10.1021/acs.bioconjchem.5b00152

13. Hanaoka, K.; Kagami, Y.; Piao, W.; Myochin, T.; Numasawa, K.; Kuriki, Y.; Ikeno, T.; Ueno, T.; Komatsu, T.; Terai, T.; Nagano, T.; Urano, Y. Chem. Commun. 2018, 54, 6939-6942. doi:10.1039/c8cc02451k

14. Du, M.; Huo, B.; Liu, J.; Li, M.; Fang, L.; Yang, Y. Anal. Chim. Acta 2018, 1030, 172-182. doi:10.1016/j.aca.2018.05.013

15. Koide, Y.; Urano, Y.; Hanaoka, K.; Terai, T.; Nagano, T. ACS Chem. Biol. 2011, 6, 600-608. doi:10.1021/cb1002416 16. Wang, T.; Zhao, Q.-J.; Hu, H.-G.; Yu, S.-C.; Liu, X.; Liu, L.; Wu, Q.-Y. Chem. Commun. 2012, 48, 8781-8783. doi:10.1039/c2cc34159j

17. Wang, B.; Cui, X.; Zhang, Z.; Chai, X.; Ding, H.; Wu, Q.; Guo, Z.; Wang, T. Org. Biomol. Chem. 2016, 14, 6720-6728. doi:10.1039/c6ob00894a

18. Egawa, T.; Hanaoka, K.; Koide, Y.; Ujita, S.; Takahashi, N.; Ikegaya, Y.; Matsuki, N.; Terai, T.; Ueno, T.; Komatsu, T.; Nagano, T. J. Am. Chem. Soc. 2011, 133, 14157-14159. doi:10.1021/ja205809h

19. Huang, Y.-L.; Walker, A. S.; Miller, E. W. J. Am. Chem. Soc. 2015, 137, 10767-10776. doi:10.1021/jacs.5b06644 
20. Zhang, H.; Liu, J.; Liu, C.; Yu, P.; Sun, M.; Yan, X.; Guo, J.-P.; Guo, W. Biomaterials 2017, 133, 60-69. doi:10.1016/j.biomaterials.2017.04.023

21. Huo, Y.; Miao, J.; Han, L.; Li, Y.; Li, Z.; Shi, Y.; Guo, W. Chem. Sci. 2017, 8, 6857-6864. doi:10.1039/c7sc02608k

22. Koide, Y.; Urano, Y.; Hanaoka, K.; Terai, T.; Nagano, T. J. Am. Chem. Soc. 2011, 133, 5680-5682. doi:10.1021/ja111470n

23. Umezawa, K.; Yoshida, M.; Kamiya, M.; Yamasoba, T.; Urano, Y. Nat. Chem. 2017, 9, 279-286. doi:10.1038/nchem.2648

24. Grimm, J. B.; English, B. P.; Chen, J.; Slaughter, J. P.; Zhang, Z.; Revyakin, A.; Patel, R.; Macklin, J. J.; Normanno, D.; Singer, R. H.; Lionnet, T.; Lavis, L. D. Nat. Methods 2015, 12, 244-250. doi:10.1038/nmeth.3256

25. Grimm, J. B.; Muthusamy, A. K.; Liang, Y.; Brown, T. A.; Lemon, W. C.; Patel, R.; Lu, R.; Macklin, J. J.; Keller, P. J.; Ji, N.; Lavis, L. D. Nat. Methods 2017, 14, 987-994. doi:10.1038/nmeth.4403

26. Chi, W.; Qiao, Q.; Lee, R.; Liu, W.; Teo, Y. S.; Gu, D.; Lang, M. J.; Chang, Y.-T.; Xu, Z.; Liu, X. Angew. Chem., Int. Ed. 2019, 58, 7073-7077. doi:10.1002/anie.201902766

27. Ikeno, T.; Nagano, T.; Hanaoka, K. Chem. - Asian J. 2017, 12, 1435-1446. doi:10.1002/asia.201700385

28. Lavis, L. D.; Raines, R. T. ACS Chem. Biol. 2008, 3, 142-155. doi:10.1021/cb700248m

29. Savarese, M.; Aliberti, A.; De Santo, I.; Battista, E.; Causa, F.; Netti, P. A.; Rega, N. J. Phys. Chem. A 2012, 116, 7491-7497. doi:10.1021/jp3021485

30. Zhao, N.; Xuan, S.; Fronczek, F. R.; Smith, K. M.; Vicente, M. G. H J. Org. Chem. 2017, 82, 3880-3885. doi:10.1021/acs.joc.6b02981

31. Hirabayashi, K.; Hanaoka, K.; Takayanagi, T.; Toki, Y.; Egawa, T.; Kamiya, M.; Komatsu, T.; Ueno, T.; Terai, T.; Yoshida, K.; Uchiyama, M.; Nagano, T.; Urano, Y. Anal. Chem. (Washington, DC, U. S.) 2015, 87, 9061-9069. doi:10.1021/acs.analchem.5b02331

32. Grimm, J. B.; Brown, T. A.; Tkachuk, A. N.; Lavis, L. D. ACS Cent. Sci. 2017, 3, 975-985. doi:10.1021/acscentsci.7b00247

33. Fischer, C.; Sparr, C. Angew. Chem., Int. Ed. 2018, 57, 2436-2440. doi:10.1002/anie.201711296

34. Kolmakov, K.; Hebisch, E.; Wolfram, T.; Nordwig, L. A.; Wurm, C. A.; Ta, H.; Westphal, V.; Belov, V. N.; Hell, S. W. Chem. - Eur. J. 2015, 21, 13344-13356. doi:10.1002/chem.201501394

35. Zhang, H.; Li, K.; Li, L.-L.; Yu, K.-K.; Liu, X.-Y.; Li, M.-Y.; Wang, N.; Liu, Y.-H.; Yu, X.-Q. Chin. Chem. Lett. 2019, 5, 1063-1066. doi:10.1016/j.cclet.2019.03.017

36. Dolci, L.; Dolle, F.; Jubeau, S.; Vaufrey, F.; Crouzel, C. J. Labelled Compd. Radiopharm. 1999, 42, 975-985. doi:10.1002/(sici)1099-1344(199910)42:10<975::aid-jlcr256>3.0.co;2-e

37. Olberg, D. E.; Arukwe, J. M.; Grace, D.; Hjelstuen, O. K.; Solbakken, M.; Kindberg, G. M.; Cuthbertson, A. J. Med. Chem. 2010, 53, 1732-1740. doi:10.1021/jm9015813

38. Naumiec, G. R.; Cai, L.; Lu, S.; Pike, V. W. Eur. J. Org. Chem. 2017, 6593-6603. doi:10.1002/ejoc.201700970

39. Zielonka, J.; Joseph, J.; Sikora, A.; Hardy, M.; Ouari, O.; Vasquez-Vivar, J.; Cheng, G.; Lopez, M.; Kalyanaraman, B. Chem. Rev. 2017, 117, 10043-10120. doi:10.1021/acs.chemrev.7b00042

40. Murphy, M. P. Biochim. Biophys. Acta, Bioenerg. 2008, 1777, 1028-1031. doi:10.1016/j.bbabio.2008.03.029

41. Murphy, M. P.; Smith, R. A. J. Adv. Drug Delivery Rev. 2000, 41, 235-250. doi:10.1016/s0169-409x(99)00069-1
42. Murayama, C.; Kawaguchi, A. T.; Kamijo, A.; Naito, K.; Kanazawa, M.; Tsukada, H. PLoS One 2017, 12, e0170911.

doi:10.1371/journal.pone.0170911

43. Li, J.; Lu, J.; Zhou, Y. BioMed Res. Int. 2017, No. 5246853. doi:10.1155/2017/5246853

44. Rideout, D. C.; Calogeropoulou, T.; Jaworski, J. S.; Dagnino, R., Jr.; McCarthy, M. R. Anticancer Drug Des. 1989, 4, 265-280.

45. Murphy, M. P. Trends Biotechnol. 1997, 15, 326-330. doi:10.1016/s0167-7799(97)01068-8

46. Sung, J.; Rho, J. G.; Jeon, G. G.; Chu, Y.; Min, J. S.; Lee, S.; Kim, J. H.; Kim, W.; Kim, E. Bioconjugate Chem. 2019, 30, 210-217. doi:10.1021/acs.bioconjchem.8b00845

47. Mallet, M.; Quéguiner, G. Tetrahedron 1979, 35, 1625-1631. doi:10.1016/0040-4020(79)80026-5

48. Miller, R. E.; Rantanen, T.; Ogilvie, K. A.; Groth, U.; Snieckus, V. Org. Lett. 2010, 12, 2198-2201. doi:10.1021/ol100493v

49. Schnürch, M.; Spina, M.; Khan, A. F.; Mihovilovic, M. D.; Stanetty, P. Chem. Soc. Rev. 2007, 36, 1046-1057. doi:10.1039/b607701n

50. Schlosser, M. Angew. Chem., Int. Ed. 2005, 44, 376-393. doi:10.1002/anie.200300645

51. Erb, W.; Mongin, F. Tetrahedron 2016, 72, 4973-4988. doi:10.1016/j.tet.2016.06.078

52. Hell, S. W.; Wichmann, J. Opt. Lett. 1994, 19, 780-782. doi:10.1364/ol.19.000780

53. Hell, S. W. Science 2007, 316, 1153-1158. doi:10.1126/science.1137395

54. Giedt, R. J.; Fumene Feruglio, P.; Pathania, D.; Yang, K. S.; Kilcoyne, A.; Vinegoni, C.; Mitchison, T. J.; Weissleder, R. Sci. Rep. 2016, 6, No. 32985. doi:10.1038/srep32985

55. Erdmann, R. S.; Takakura, H.; Thompson, A. D.; Rivera-Molina, F.; Allgeyer, E. S.; Bewersdorf, J.; Toomre, D.; Schepartz, A. Angew. Chem., Int. Ed. 2014, 53, 10242-10246. doi:10.1002/anie.201403349

56. Lukinavičius, G.; Blaukopf, C.; Pershagen, E.; Schena, A.; Reymond, L.; Derivery, E.; Gonzalez-Gaitan, M.; D’Este, E.; Hell, S. W.; Wolfram Gerlich, D.; Johnsson, K. Nat. Commun. 2015, 6, 8497. doi:10.1038/ncomms9497

57. Lukinavičius, G.; Reymond, L.; D'Este, E.; Masharina, A.; Göttfert, F.; Ta, H.; Güther, A.; Fournier, M.; Rizzo, S.; Waldmann, H.; Blaukopf, C.; Sommer, C.; Gerlich, D. W.; Arndt, H.-D.; Hell, S. W.; Johnsson, K. Nat. Methods 2014, 11, 731-733. doi:10.1038/nmeth.2972

58. Yang, X.; Yang, Z.; He, Y.; Shan, C.; Yan, W.; Wu, Z.; Chai, P.; Teng, J.; Qu, J.; Xi, P. bioRxiv 2019, 646117. doi:10.1101/646117 


\section{License and Terms}

This is an Open Access article under the terms of the Creative Commons Attribution License (http://creativecommons.org/licenses/by/4.0). Please note that the reuse, redistribution and reproduction in particular requires that the authors and source are credited.

The license is subject to the Beilstein Journal of Organic Chemistry terms and conditions:

(https://www.beilstein-journals.org/bjoc)

The definitive version of this article is the electronic one which can be found at:

doi:10.3762/bjoc. 15.226 